\title{
Paris in Spring
}

Although a long-term agreement was not reached between AGU, ASLO, and TOS, we have an Interim Agreement for the 2006 and 2008 Ocean Sciences Meeting. We will continue to try and resolve key differences between AGU's views and those of TOS and ASLO. All three societies agreed to a date of October 31, 2004 to have a signed MOU in place, but if not, ASLO and TOS will continue to sponsor a joint biennial meeting in 2005 for the ocean community.

As I write this column, the U.S. Commission on Ocean Policy's preliminary report has just been released, and sent out to all U.S. governors for review and comment. This $600+$ page report (available at http://www.oceancommission.gov/) is the first major ocean report since the Stratton Commission report came out in 1969, one outcome of which was the creation of NOAA. The present Ocean Commission report represents a major effort by a large number of scientists, educators, policy-makers, politicians, states, people in industry, and other citizens, all interested in the U.S. national ocean agenda and its future direction. It came out during an election year so there has been speculation as to whether the report will be disregarded or used by Congress and the Administration. The answer, of course, is that it will be used as much (or as little) as required to satisfy the "voices" heard from the constituencies. Don't forget you are one of these "voices" and can impact the implementation of the report by passing on your views to your elected officials, institutions, and others.

TOS would like to initiate broader dialogue on this report and plans to have Oceanography print at least one article in the September 2004 issue (17-3), and perhaps in future issues, examining the report. I encourage you to independently, or with your colleagues, review this report-and submit for review and possible publication-your own analysis or "sense of the report." Please submit your review to Mel Briscoe (briscom@onr.navy.mil), who has agreed to act as a special editor for these articles, or to the magazine editor Ellen Kappel (ekappel@geo-prose.com). It can only help to have a broader national dialogue on this report. Oceanography is distributed to key congressional members and staffers, so these articles would get directly to them.
As President I would be remiss if I didn't encourage all TOS members to take an active interest in the Society's affairs and events. As reported in my last column much has been accomplished over the past couple of years: a new Fellows Program is being implemented; a phased plan for more complete electronic, Web-based communication is being completed; driven by the changes in presentation technology, the hugely successful Scientifically Speaking publication is being updated; a joint ASLO/TOS conference has been completed; there has been a continuing effort to try to bring AGU into the mix; a new magazine editor is in place, maintaining four publications a year of the magazine; and finally, the Society is on a more stable financial footing.

However, there is one matter that remains incomplete that needs your active involvement: the recruitment of new members to TOS. A Society needs new members not only to maintain itself, but also to remain vigorous and enhance services for members and the broader community. The TOS Council has passed a motion to start a membership drive with the goal of at least doubling our membership by 2008. This goal is achievable and your Council will personally take steps to help reach it. The membership drive also plans to ask the Society's historically strong supporters, its Life Members, to actively recruit new members. TOS looks to all its members who recognize the value of the Society to the oceanographic community to reach out to colleagues and students and encourage them to become TOS members. Simply print copies of the membership application form from the TOS web page (www.tos.org), give them to your colleagues and students, and make sure they are filled out and returned.

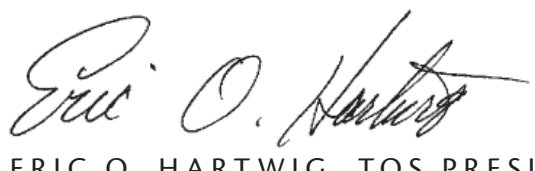

ERIC O. HARTWIG, TOS PRESIDENT 